\title{
Autonomía médica en tiempos de pandemia. Desafíos y oportunidades
}

\author{
Medical autonomy in pandemic's times. Challenges and opportunities
}

Acosta $A S^{1}$.

${ }^{1}$ Médica internista, endocrinóloga. Miembro de número, Asociación Colombiana de Endocrinología, Diabetes y Metabolismo. Miembro, comité editorial, Revista Colombiana de Endocrinología, Diabetes y Metabolismo.

$\mathrm{E}$ n esta pandemia, la autonomía médica ha tenido uno de los mayores retos de las últimas décadas, debido al escaso conocimiento y a la ausencia de evidencia para el tratamiento del SARS-CoV-2. Ante esto, surge la pregunta ¿cómo las pandemias han afectado la autonomía médica?

Aprovechar la experiencia de otras pandemias supondría un conocimiento y preparación que debería disminuir el número de contagios y el número de vidas perdidas. Por ejemplo, al tratarse de enfermedades que se contagian por el aire, el uso del tapabocas ha sido considerado esencial. En las plagas que azotaron a Europa en el siglo XIV y XVII, los médicos diseñaron atuendos de protección, que fueron retados por sus colegas. Posterior a 1861, con la confirmación de Pasteur sobre patógenos en el aire, los médicos prescribieron tapabocas de algodón para evitar el contagio. Esto se replicó en 1918 con la pandemia conocida como gripe española.

El hecho de retardar el uso del tapabocas, en un momento en que el desarrollo tecnológico y la informática permitieron tener la secuencia del SARS-CoV-2 en menos de 2 semanas, hace un llamado a la reflexión. Publicaciones afirman que ese retraso se debió a la ausencia de evidencia $(1,2)$.

La autonomía es uno de los principios de la ética médica, junto con la beneficencia, la no maleficencia y la justicia. Esta autonomía se ejerce basada en la autorregulación, la racionalidad científica y la evidencia. En tiempos de pandemia, estos principios también deben permanecer centrales en nuestro quehacer médico, aunque en este momento se reconoce globalmente que han estado sujetos a presión (3).

En la década de los 90 hubo un gran reto a los principios de la medicina basada en la evidencia y para rescatarla y tras- ladarla al ejercicio médico se enmarcó en tres principios: la evidencia científica, el juicio clínico y la voluntad del paciente.

Gordon Smith y colaboradores publicaron un ensayo clínico aleatorizado sobre la eficacia del uso del paracaídas, el cual generó múltiples opiniones, no por el sarcasmo, sino por la rigurosidad de los métodos y una forma de enseñar qué es y qué no es la medicina basada en evidencia. Mirsky, en 2019, señaló como lección la relevancia de hacer la pregunta correcta y elegir la metodología adecuada y la inutilidad de los estudios clínicos, aleatorizados y doble ciegos para hacer conclusiones razonables sobre ciertos efectos en ciertas acciones (4-6).

Sackett afirma que la medicina basada en la evidencia es una referencia de excelencia que guía las decisiones clínicas e integra la excelencia propia del clínico con la de otros; es una forma de mejorar la práctica médica, limitando la variabilidad y los errores que esto acarrea. No consiste en suprimir la libertad clínica, no debe convertir la práctica médica en mandatoria, determinista y totalitarista, tampoco debe ser una barrera para no hacer nada cuando no existe evidencia o un instrumento político o económico o una vía de control de gastos que ignore las preferencias de los pacientes (7).

De ninguna manera esto quiere decir que no se utilice la evidencia y se gradué, como lo dicen las actuales guías (Grade), si están disponibles.

En Colombia, la autonomía médica está amparada por la Ley 1751 de 2015, una ley con fuerza constitucional, que en su artículo 17 establece: "Se garantiza la autonomía de los profesionales de la salud para adoptar decisiones sobre el diagnóstico y tratamiento de los pacientes que tienen a su cargo. Esta autonomía será ejercida en el marco de esquemas de autorregulación, la ética, la racionalidad y la evidencia científica. Se prohíbe todo constreñimiento, presión o restricción del ejercicio profesional que atente contra la autonomía de los profesionales de la salud, así como cualquier abuso en el ejercicio profesional que atente contra la seguridad del paciente". 
El trabajo incansable y sacrificado de los profesionales de la salud en el campo de batalla ha llevado al progreso de la ciencia, mientras ejercen su mejor juicio a favor de los pacientes durante las pandemias. La autonomía médica debe ser salvaguarda, aun cuando las acciones terapéuticas son reducidas, y debemos reconocer el riesgo de no poner en práctica los principios de la ética médica, que por las características de esta pandemia han producido y producirán daños a la humanidad $(8,9)$.

En pandemia y sin pandemia, la medicina es y seguirá siendo el arte y la ciencia de la que nos enamoramos.

\section{Referencias}

1. Yong-Zhen Z, Holmes E. A Genomic Perspective on the Origin and Emergence of SARS-CoV-2. Cell. 2020;181(2):223-7. doi: 10.1016/j. cell.2020.03.035

2. Jefferson T, Heneghan C. Masking lack of evidence with politics [Internet]. CEBM; 2020. Disponible en: https://bit.ly/3nyIW3E

3. Robert R, Kentish-Barnes N, Boyer A, Laurent A, Azoulay E, Reignier J. Ethical dilemmas due to the Covid-19 pandemic. Ann Intensive Care. 2020;10(1):84. doi: 10.1186/s13613-020-00702-7

4. Smith GCS, Pell JP. Parachute use to prevent death and major trauma related to gravitational challenge: systematic review of randomised controlled trials. BMJ. 2003;327(7429):1459-61. doi: 10.1136/bmj.327.7429.1459

5. Mirsky S. Volunteers Jumped with or without a Parachute to Gauge Its Effectiveness. Someone finally did a study on the efficacy of parachutes. Scientific American 2019;175. Disponible en: https://bit.ly/2WuV2z3
6. Koenig K. Comment: Common Sense vs. Evidence-Based Medicine: Lessons from the Parachute. NEJM. 2004. Disponible en: https://bit.ly/3mzXWNo

7. Sackett D, Rosenberg W, Gray J, Haynes R, Richardson W. Evidence based medicine: what it is and what it isn't. BMJ. 1996;312(7023):71-2. doi: $10.1136 / \mathrm{bmj} .312 .7023 .71$

8. Djulbegovic B, Guyatt G. Evidenced-based medicine in times of crisis. J Clin Epidemiol. 2020;126:164-6. doi: 10.1016/j.jclinepi.2020.07.002

9. Malm H, May T, Francis LP, Omer S, Salmon D, Hood R. Ethics, Pandemics, and the Duty to Treat. Am J Bioet. 2008;8(8):4-19. doi: $10.1080 / 1526516080231797$ 


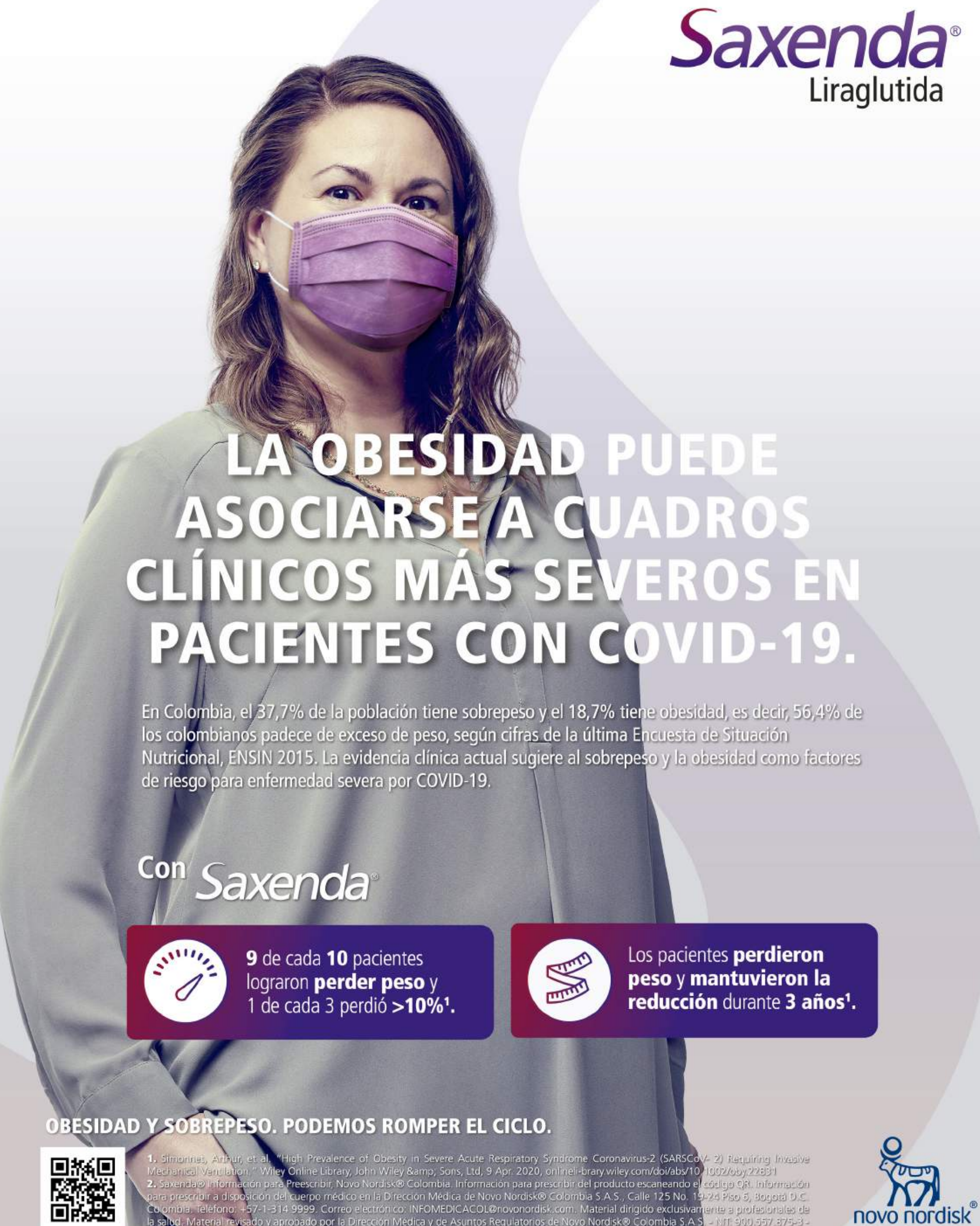

